University of Nebraska - Lincoln

DigitalCommons@University of Nebraska - Lincoln

2009

\title{
Improved Sugar Conversion and Ethanol Yield for Forage Sorghum (Sorghum bicolor L. Moench) Lines with Reduced Lignin Contents
}

\author{
Bruce S. Dien \\ USDA-ARS, Bruce.Dien@ars.usda.gov \\ Gautam Sarath \\ University of Nebraska - Lincoln, Gautam.sarath@ars.usda.gov \\ Jeffrey F. Pedersen \\ University of Nebraska-Lincoln, jpedersen1@unl.edu \\ Scott E. Sattler \\ University of Nebraska-Lincoln, Scott.Sattler@ars.usda.gov \\ Han Chen \\ University of Nebraska-Lincoln, hchen3@unl.edu \\ See next page for additional authors \\ Follow this and additional works at: https://digitalcommons.unl.edu/biochemistrysarath \\ Part of the Biochemistry, Biophysics, and Structural Biology Commons
}

Dien, Bruce S.; Sarath, Gautam; Pedersen, Jeffrey F.; Sattler, Scott E.; Chen, Han; Funnell-Harris, Deanna L.; Nichols, Nancy N.; and Cotta, Michael A., "Improved Sugar Conversion and Ethanol Yield for Forage Sorghum (Sorghum bicolor L. Moench) Lines with Reduced Lignin Contents" (2009). Gautam Sarath Publications. 12.

https://digitalcommons.unl.edu/biochemistrysarath/12

This Article is brought to you for free and open access by the Biochemistry, Department of at DigitalCommons@University of Nebraska - Lincoln. It has been accepted for inclusion in Gautam Sarath Publications by an authorized administrator of DigitalCommons@University of Nebraska - Lincoln. 


\section{Authors}

Bruce S. Dien, Gautam Sarath, Jeffrey F. Pedersen, Scott E. Sattler, Han Chen, Deanna L. Funnell-Harris, Nancy N. Nichols, and Michael A. Cotta 


\title{
Improved Sugar Conversion and Ethanol Yield for Forage Sorghum (Sorghum bicolor L. Moench) Lines with Reduced Lignin Contents
}

\author{
Bruce S. Dien • Gautam Sarath • Jeffrey F. Pedersen • Scott E. Sattler • Han Chen • \\ Deanna L. Funnell-Harris • Nancy N. Nichols • Michael A. Cotta
}

Published online: 8 August 2009

(C) US Government 2009

\begin{abstract}
Lignin is known to impede conversion of lignocellulose into ethanol. In this study, forage sorghum plants carrying brown midrib (bmr) mutations, which reduce lignin contents, were evaluated as bioenergy feedstocks. The near-isogenic lines evaluated were: wild type, $b m r-6, b m r-12$, and $b m r-6 b m r-12$ double mutant. The $b m r-$ 6 and $b m r-12$ mutations were equally efficient at reducing lignin contents (by 13\% and 15\%, respectively), and the effects were additive (27\%) for the double mutant. Reducing lignin content was highly beneficial for improving biomass conversion yields. Sorghum biomass samples were pretreated with dilute acid and recovered solids washed and hydrolyzed with cellulase to liberate glucose. Glucose yields for the sorghum biomass were improved by
\end{abstract}

Supplier names are necessary to report factually on available data; however, the USDA neither guarantees nor warrants the standard of the product, and the use of the name by USDA implies no approval of the product to the exclusion of others that may also be suitable.

B. S. Dien $(\square) \cdot$ N. N. Nichols $\cdot$ M. A. Cotta

Fermentation Biotechnology Research Unit,

National Center for Agricultural Utilization Research,

Agricultural Research Service,

United States Department of Agriculture,

1815 N. University Street,

Peoria, IL 61604, USA

e-mail: Bruce.Dien@ars.usda.gov

G. Sarath · J. F. Pedersen · S. E. Sattler • D. L. Funnell-Harris

Grain, Forage, and Bioenergy Research Unit,

Agricultural Research Service,

United States Department of Agriculture,

Biochemistry Hall, University of Nebraska, East Campus,

Lincoln, NE 68583-0737, USA

H. Chen

Microscopy Facility, E-119 Beadle, Center for Biotechnology,

University of Nebraska-Lincoln,

Lincoln, NE 68588-0665, USA
$27 \%, 23 \%$, and $34 \%$ for $b m r-6, b m r-12$, and the double mutant, respectively, compared to wild type. Sorghum biomass was also pretreated with dilute acid followed by co-treatment with cellulases and Saccharomyces cerevisiae for simultaneous saccharification and fermentation (SSF) into ethanol. Conversion of cellulose to ethanol for diluteacid pretreated sorghum biomass was improved by $22 \%$, $21 \%$, and $43 \%$ for $b m r-6, b m r-12$, and the double mutant compared to wild type, respectively. Electron microscopy of dilute-acid treated samples showed an increased number of lignin globules in double-mutant tissues as compared to the wild-type, suggesting the lignin had become more pliable. The mutations were also effective for improving ethanol yields when the (degrained) sorghum was pretreated with dilute alkali instead of dilute acid. Following pretreatment with dilute ammonium hydroxide and SSF, ethanol conversion yields were 116 and $130 \mathrm{mg}$ ethanol/g dry biomass for the double-mutant samples and 98 and $113 \mathrm{mg} / \mathrm{g}$ for the wild-type samples.

Keywords Bioenergy crops · Bioethanol · Brown midrib . Lignin $\cdot$ Sorghum bicolor

\section{Introduction}

There is a resurgent interest in renewable fuels as means to dampen price volatility in transportation fuels, mediate economic and security concerns related to importing oil from a small cohort of producers, and reduce carbon dioxide emissions along with associated risks of climate change and global oceanic acidification. As a consequence, ethanol production capacity in the USA has more than tripled in the past 5 years expanding from 3.4 (2004) to 10 billion gallons (2009) (Renewable Fuel Association; www.ethanolrfa.org; 
accessed on Jan. 12, 2009). Almost all of US ethanol is manufactured from corn grain, and producing 10 billion gallons of ethanol would consume over $30 \%$ of the corn harvest [37]. By contrast, this amount of ethanol would only reduce domestic gasoline demand by $4.8 \% \mathrm{~J} / \mathrm{J}$. Therefore, additional feedstocks need to be developed for ethanol production, and only lignocellulose is available in quantities that rival corn. Lignocellulosic feedstocks include agricultural residues, forestry and wood pulp wastes, and energy crops. A governmental study estimates that enough lignocellulose can be made available to substitute $30 \% \mathrm{~J} / \mathrm{J}$ of the US petroleum consumption with biofuels [25]. Life cycle analysis studies estimate that biofuels derived from lignocellulose have a high net energy output and are effective for reducing net carbon dioxide emissions [12].

Forage sorghum has attracted interest as a potential energy crop. It can be grown under conditions that are unfavorable for corn production, is already established as an industrial crop, and has high biomass yields - sorghum plants can grow $6-15 \mathrm{ft}$ tall $[28,33]$. Forage sorghum is grown on 6 million acres in the USA (2007) with a total production of 58 million tons of biomass. Of particular interest are the brown midrib (bmr) varieties, which have lower lignin contents and increased forage quality (e.g., rumen digestibility) $[20,21,26]$. Plants carrying the $b m r$ mutations are named for the characteristic reddish brown coloration present in the vascular plant tissue. Sorghum $b m r$ mutants were first isolated from a chemically mutagenized population at Purdue University [26], and three (bmr-6, $b m r-12$, and $b m r-18$ ) have been incorporated into commercial lines [28]. They are recommended for use as bioenergy crops because it is reasonable to suppose that their reduced lignin contents would improve sugar and ethanol yields and require less severe pretreatments.

Manufacturing ethanol from lignocelluloses is a multistep process (for review, see [6]). The biomass is milled to reduce particle size, wetted, and pretreated prior to enzyme processing. During pretreatment, the biomass is subjected to a combination of physical, thermal, and chemical conditions that open up the plant cell wall structure and expose the hemicellulose and cellulose fibers. Subsequently, the pretreated biomass is hydrolyzed to sugars using cellulases and possibly hemicellulases. When the biomass is pretreated in the presence of dilute acid (e.g., $\mathrm{H}_{2} \mathrm{SO}_{4}$ ), acid catalysis directly converts the xylan into monosaccharides. The liberated sugars are fermented to ethanol and the ethanol recovered by distillation. Alternately, enzymes and fermenting microbe are co-added, allowing the saccharified sugars to be fermented instantly; simultaneous saccharification and fermentation (SSF) minimizes end product inhibition of the enzymes and microbial contamination.

Biomass needs to be pretreated prior to saccharification because carbohydrases are unable to effectively penetrate native plant cell walls and access their targeted carbohydrates. In warm season grasses, primary cell walls are composed of cellulose, glucurono-arabinoxylans (GAX), and phenolic residues. GAX consists of a $\beta 1,4$-linked xylose backbone with arabinose and glucuronic acid side chains [34]. The $p$-coumaric and ferulic phenolic acids are bound to the arabinans through ester and ether bonds, and significantly, the ferulic acids also dimerize thereby crosslinking adjacent xylan strands [34]. The secondary cell walls are located inside of primary cell walls of vascular and supporting tissue and, in addition to cellulose and GAX, often contain lignin. Lignin is a complex hydrophobic polymer of $p$-hydroxyphenyl, guaiacyl, and syringyl residues that fills in the spaces between the cellulose fibers and hemicellulose. Lignin is highly resistant to chemical cleavage and is thought to be the major barrier protecting cellulose fibers from cellulase hydrolysis to glucose [3]. Lignin retards the action of cellulases in multiple ways: acting as a physical barrier, impeding swelling of cellulose fibers, and nonspecifically binding cellulase proteins [33]. Therefore, reducing lignin content of plants could potentially increase sugar yields, allow for reduced pretreatment severity, and possibly lower enzyme loadings. Two recent papers demonstrate that $b m r$ mutations appearing singly promote increased glucose yields when dilute-acid pretreated samples are hydrolyzed with cellulases [5, 27]. What has not yet been investigated is the direct impact of $b m r$ mutations on ethanol yields.

In the present study, we investigated near-isogenic $b m r-6, b m r-12$, and $b m r-6 b m r-12$ mutants as bioenergy crops. This is the first report on the use of a double $b m r$ sorghum mutant for ethanol production. $b m r-6$ encodes for a cinnamylalcohol dehydrogenase [29], and $b m r-12$ encodes an $O$-methyl-transferase that is apparently specific to 5-hydoxyconiferyl aldehyde [2,23]. Both $b m r-6$ and $b m r-12$ are null mutations leading to the absence of active enzymes in tissues [23, 29]. Loss of enzyme activity results in increased soluble phenolics and lower incorporation of $p$-coumaric and ferulic acids as well as lignin into cell walls, where the greatest effect is observed in $b m r-6$ bmr-12 plants [23]. In these plants, lignification in stem tissues was also significantly impaired [23, 29]. Lowered total lignin in some of these near-isogenic lines has been correlated to increased dry matter digestibility by ruminants $[20,21,24]$. Here, we evaluated the effect of diluteacid pretreatment of the three mutants ( $b m r-6, b m r-12$, and $b m r-6 b m r-12$ genotypes) and the parental line for conversion to glucose and ethanol, where ethanol yields were measured by SSF cultures using the yeast Saccharomyces cerevisiae. The effect of the bmr-6 bmr-12 genotype on ethanol yield was further investigated using a promising alkaline pretreatment. 


\section{Materials and Methods}

Enzymes and Chemicals

Cellulase GC220 was kindly donated by Genencor, Inc. (Rochester, NY) and Novo188 $\beta$-glucosidase (Novozymes A/S, Denmark) was purchased from Sigma Chemicals (St. Louis, MO). Other reagents and chemicals were purchased from Sigma Chemicals or Fisher Scientific (Pittsburgh, PA) and were research quality.

\section{Sorghum Biomass}

Development of the single- and double-mutant stocks has been previously described [24]. Lines of the cultivar Atlas near-isogenic for the single- and double-mutant stocks were grown at the University of Nebraska Agricultural Research and Development fields near Lincoln, NE, in the summer of 2005. Seeds from individual genotypes were planted in a randomized complete block design on March 18. Plots consisted of three $7.6-\mathrm{m}$ rows spaced $76 \mathrm{~cm}$ apart. Each plot was seeded with a precision vacuum planter calibrated to deliver 120 seeds per row $(240,000$ seeds $\left.\mathrm{ha}^{-1}\right)$. Propachlor [2-chloro- $N$-(1-methylethyl)$N$-phenylacetamide] and atrazine [6-chloro- $n$-ethyl- $N$ '(1-methylethyl)-1,3,5-triazine-2,4,diamine] were applied at 3.36 and $1.1 \mathrm{~kg} \mathrm{ha}^{-1}$, respectively, immediately after planting for weed control. After all plots reached the harddough stage of maturity, duplicate plots were harvested on September 29 to yield plants with grain or after removal of the seed heads to give plants without grain. Plants were harvested with a flail chopper, and plant materials were subsequently oven dried at $50^{\circ} \mathrm{C}$ and ground to pass through a $1-\mathrm{mm}$ screen using a Wiley mill.

\section{Compositional Analysis}

Starch was estimated following treatment with amylases [14]. Structural carbohydrates (cellulose, xylan, and arabinan), Klason lignin, and ash were determined according to the analytical procedure of the National Renewable Energy Laboratory (NREL) [31]. Lipid content was determined by exhaustive extraction with hexane. Nitrogen content was determined by combustion, and crude protein concentration was estimated as Nx6.25 [22]. Soluble sugars were extracted in water by treating in an ultrasound bath for $5 \mathrm{~min}$ and measured by HPLC. Samples were processed for detergent fiber analysis according to standard methods [32]. Measurements included neutral detergent fiber (NDF), acid detergent fiber (ADF), and acid detergent lignin (ADL). Detergent hemicellulose (xylan) was estimated from the difference of $\mathrm{ADF}$ and $\mathrm{NDF}$ and detergent cellulose from the difference of ADF and ADL.
Dilute-Acid Pretreatment, Enzymatic Hydrolysis, and Ethanol Fermentation

Sorghum samples were pretreated in dilute sulfuric acid solution $(1.75 \% w / v)$ by combining $1 \mathrm{~g}$ with $9.0 \mathrm{ml}$ acid buffer (5\% w/v solid loading) for digestion experiments and $1.5 \mathrm{~g}$ with $8.5 \mathrm{ml}$ acid buffer $(15 \% \mathrm{w} / v$ solid loading) for fermentation experiments. Corning Pyrex ${ }^{\mathrm{TM}}$ solution bottles $(25 \mathrm{ml})$ were used as reaction vessels, and lids were tightened prior to heating. Samples were heated at $121^{\circ} \mathrm{C}$ in an autoclave for an hour. Solids were recovered by centrifugation $(23,000 \times g$ for $20 \mathrm{~min})$ and washed three times with equal volumes of distilled water, once again using centrifugation to recover the pellet between washes.

Cellulose digestibility was determined using a modified version of a NREL procedure [30]. The suspected pellet was weighed and brought up to a final weight of $15 \mathrm{~g}$ by addition of sodium citrate buffer $(50 \mathrm{mM}, \mathrm{pH} 4.8)$ supplemented with the antibacterial agent thymol (350 $\mathrm{mg} / \mathrm{l})$. The enzymatic digestion was initiated by adding GC220 cellulase (50 FPU/g cellulose) and Novo188 $\beta$-glucosidase (40 U/g cellulose). The reaction was conducted at $50^{\circ} \mathrm{C}$ for $72 \mathrm{~h}$ while stirring at $125 \mathrm{rpm}$ using an incubator/shaker (Innova ${ }^{\circledR}$, New Brunswick Scientific, NJ). Following $72 \mathrm{~h}$, the digestion was sampled and analyzed for soluble carbohydrates and monosaccharides.

Ethanol efficiencies were determined using a modified version of the NREL procedure [11]. The recovered pellet was diluted with $18 \mathrm{ml}$ of sodium citrate buffer $(50 \mathrm{mM}$, $\mathrm{pH} 4.8$ ) and $2 \mathrm{ml}$ of yeast extract and peptone solution (YP, $10 \mathrm{~g} / \mathrm{l}$ yeast extract and $20 \mathrm{~g} / \mathrm{l}$ peptone final concentrations). Next, the following enzymes were added: GC220 Cellulase (15 FPU/g cellulose) and Novo188 $\beta$-glucosidase (40 U/g cellulose). The enzyme loadings are reduced from those used for the digestions because fermentations were conducted to minimize end product inhibition. The culture was inoculated with $S$. cerevisiae D5A (ATCC200062) to a beginning $\mathrm{OD}_{600}$ of 0.5 . The fermentation flask was capped with a rubber stopper, which was pierced with a $22-\mathrm{g}$ needle to allow for $\mathrm{CO}_{2}$ to exhaust. The simultaneous saccharification and fermentation culture was incubated at $35^{\circ} \mathrm{C}$ for $72 \mathrm{~h}$ while mixing at $125 \mathrm{rpm}$, also using an Innova shaker/incubator. The inoculum was prepared by transferring a colony grown on solid YP2D (YP supplemented with $20 \mathrm{~g} / 1$ dextrose and $2.0 \%$ Bacto agar) to a liquid YP5D (YP supplemented with $50 \mathrm{~g} / 1$ dextrose). The liquid culture was grown $18 \mathrm{~h}$ at $35^{\circ} \mathrm{C}$ and $200 \mathrm{rpm}$, and the cells were harvested by centrifugation and suspended as a concentrated cell solution $\left(50 \mathrm{OD}_{600}\right)$ in diluent (saline, phosphate, peptone $(0.4 \%)$ ). Following the fermentation, the cultures were analyzed for ethanol and glucose concentrations. 
Alkaline Pretreatment and Fermentation

Sorghum samples were treated at $15 \% \mathrm{w} / \mathrm{w}$ solids in $4.0 \%$ ammonium hydroxide solution at $170^{\circ} \mathrm{C}$ for $20 \mathrm{~min}$. The reactions were conducted using stainless steel tube reactors and a fluidized heating bath previously described for diluteacid pretreatments [7]. After cooling, samples were air dried at $25^{\circ} \mathrm{C}$ for $48 \mathrm{~h}$ to remove ammonia. Dried biomass was suspended at $13.6 \% \mathrm{w} / \mathrm{w}$ solids in sodium citrate buffer (pH 4.8, $50 \mathrm{mM}$ ) and YP. Cellulase GC220 (15 FPU/g cellulose), Novo188 $\beta$-glucosidase (40 U/g cellulose), and glucoamylase Distillase L-400 (14.7 mg/g biomass, Genencor Inc.) were added and the culture fermented as described above for dilute-acid pretreated samples. Fermentations were ended following $72 \mathrm{~h}$ and broths analyzed for glucose, xylose, and ethanol concentrations.

\section{Analytical Methods}

Cellulase and $\beta$-glucosidase activities were measured as previously reported [7, 9]. Total soluble carbohydrates were analyzed by HPLC after being hydrolyzed by treating with $2 \mathrm{~N}$ trifluoroacetic acid for $60 \mathrm{~min}$ at $100^{\circ} \mathrm{C}$. Samples were analyzed for sugars and acetic acid using a HPLC equipped with an organic acids column (Bio-Rad Laboratories, CA) and a refractive index detector, as previously described [8].

\section{Calculations}

Samples were washed following dilute-acid pretreatment to remove acid and glucose released during acid hydrolysis. The glucan content of the washed pellet recovered following the pretreatment was calculated by subtracting glucose released into the hydrolysis from the beginning glucan content of the sample. Glucose efficiencies were then calculated from the ratio of glucose released following cellulase treatment and the beginning cellulose content, adjusted for the weight gained through hydrolysis. Ethanol efficiencies for fermentations of the dilute-acid pretreated samples were calculated from the ratio of ethanol produced and maximum possible ethanol. The maximum theoretical ethanol was calculated by multiplying the glucan content of the washed pellet by the theoretical conversion coefficient for ethanol production ( $0.567 \mathrm{~g}$ ethanol/g glucan). Aqueous ammonium pretreated samples were not washed prior to fermentation, and for these experiments, the ethanol yield was calculated by dividing the final amount of ethanol produced (milligrams of ethanol) by the starting biomass (grams biomass, dry basis). Compositions of the wild type, single mutants, and double mutants were compared for differences using the Duncan's multiple range test $(P<0.05)$ (SigmaStat 3.5, Systat Software, Point Richmond, CA).
Electron Microscopy

Biomass samples were dilute-acid treated as described above, washed with water, and lyophilized. Lyophilized tissues were post-treated with $1 \%$ osmium tetroxide in $0.1 \mathrm{M}$ sodium cacodylate, $\mathrm{pH} 7.4$ for $2 \mathrm{~h}$. Samples were dehydrated in a graduated ethanol and acetone series and embedded in Epon 812 (Electron Microscopic Sciences, Fort Washington, PA). Thin sections (60 nm) were stained with $2 \%$ uranyl acetate and Reynolds lead citrate and observed under a transmission electron microscope (Hitachi H7500-I) at $80 \mathrm{kv}$ at the University of Nebraska at Lincoln's Microscopy Core Facility.

\section{Results}

Compositional Results

The four sorghum genotypes analyzed were wild type, $b m r-6$, $b m r-12$, and bmr-6 bmr-12. The samples were characterized for chemical composition using the dietary fiber system (Table 1). As expected, significant variation was observed in lignin contents. For degrained sorghum samples, introducing $b m r-6$ reduced Klason lignin content by $15 \%, b m r-12$ by $15 \%$, and $b m r-6 b m r-12$ by $27 \%$ compared to the wild-type plants. A similar trend was observed for plant samples analyzed with grain intact. Interestingly, the reduction in lignin incurred by $b m r-6$ and $b m r-12$ appears to be additive when combined in the double mutant. The differences between the double-mutant plants, single $b m r$ mutant plants, and wild-type plants were all significant, but there was no significant difference between $b m r-6$ and $b m r-12$. Interestingly, crude protein was lower for the wild type vs. other genotypes, but unfortunately, the sample set was not large enough to detect a statistically significant difference. No other apparent differences were observed among the nearisogenic lines. Total carbohydrates accounted for $65 \pm 2 \%$ and $66 \pm 3 \%$ of the plants without and with grain removal. The sum of the measured properties accounted for 88.5$97.1 \%$ of the total biomass.

Samples were further analyzed for specific carbohydrate composition (Table 2). The major observable difference was, as expected, the grain-bearing samples contained approximately four times more starch compared to the degrained samples. Also, as a direct consequence of the grain-associated starch, total glucans for the plant samples with grain were $15 \%$ greater than those processed without grain. However, the total amounts of carbohydrates were similar for both sets of samples because the loss in starch was compensated by increases in the other carbohydrate components. Interestingly, differences in genotype did not appear to influence carbohydrate contents. This may appear 
Table 1 Chemical composition of sorghum plants (g per kg, dry basis)

\begin{tabular}{|c|c|c|c|c|c|c|}
\hline \multirow[t]{2}{*}{ Genotype } & Extractables & Carbohydrates & Klason lignin & Crude protein & Ash & Sum \\
\hline & \multicolumn{6}{|c|}{ Composition (g per kg, db) } \\
\hline \multicolumn{7}{|c|}{ Degrained samples } \\
\hline $\mathrm{DM}$ & 18 & $641.5 \pm 11.8$ & $112.2 \pm 8.2$ & 68 & 67.6 & 907.2 \\
\hline $\mathrm{DM}$ & 19 & $641.9 \pm 20.1$ & $100.3 \pm 1.6$ & 68 & 64.6 & 893.8 \\
\hline$b m r-6$ & 21 & $637.0 \pm 3.5$ & $129.1 \pm 5.6$ & 71 & 67.5 & 925.6 \\
\hline$b m r-6$ & 20 & $637.9 \pm 4.5$ & $119.2 \pm 3.3$ & 53 & 64.7 & 894.8 \\
\hline$b m r-12$ & 15 & $688.8 \pm 5.5$ & $125.1 \pm 2.7$ & 45 & 53.7 & 926.6 \\
\hline$b m r-12$ & 18 & $666.4 \pm 5.3$ & $128.4 \pm 3.9$ & 54 & 51.6 & 918.4 \\
\hline Wild-type & 16 & $688.2 \pm 1.9$ & $142.5 \pm 1.0$ & 41 & 53.7 & 941.4 \\
\hline Wild-type & 17 & $666.4 \pm 7.2$ & $148.8 \pm 1.1$ & 44 & 53.8 & 930.0 \\
\hline \multicolumn{7}{|c|}{ Plant samples with grain } \\
\hline $\mathrm{DM}$ & 22 & $663.0 \pm 7.1$ & $96.6 \pm 7.2$ & 65 & 64.0 & 910.5 \\
\hline $\mathrm{DM}$ & 23 & $637.0 \pm 3.3$ & $88.2 \pm 1.6$ & 78 & 58.0 & 885.2 \\
\hline$b m r-6$ & 22 & $634.9 \pm 6.0$ & $114.4 \pm 7.8$ & 67 & 57.1 & 895.4 \\
\hline$b m r-6$ & 21 & $635.1 \pm 10.0$ & $109.1 \pm 7.0$ & 65 & 60.5 & 889.6 \\
\hline$b m r-12$ & 21 & $677.5 \pm 12.5$ & $119.9 \pm 4.9$ & 68 & 41.8 & 927.2 \\
\hline$b m r-12$ & 21 & $730.0 \pm 8.8$ & $115.8 \pm 4.4$ & 61 & 44.9 & 970.7 \\
\hline Wild-type & 19 & $665.0 \pm 2.8$ & $138.7 \pm 1.8$ & 58 & 46.2 & 925.9 \\
\hline Wild-type & 19 & $694.4 \pm 14.4$ & $128.1 \pm 0.8$ & 55 & 51.1 & 945.6 \\
\hline
\end{tabular}

to be counter-intuitive given a reduction in lignin; however, lignin only comprises $14 \% \mathrm{w} / \mathrm{w}$ of the biomass content for the wild-type plants, and so even the $27 \%$ reduction observed for the double mutant only amounts to a $3.8 \%$ reduction on a whole plant mass basis.

Soluble sugars accounted for approximately one quarter of the total carbohydrates $(19 \pm 2 \% \mathrm{w} / \mathrm{w}$ biomass (degrained) and $16 \pm 2 \%$ (with grain)). Starch accounted for $18 \%$ of the carbohydrate pool for the samples with grain and only $4.4 \%$ in the no-grain plant samples. The starch content, even when including starch contributed by the grain, was less than the amount of soluble sugars. The remaining carbohydrates were all associated with the cell wall. Cellulose comprised $35 \pm 1 \%$ (with grain) and $41 \pm 1 \%$ (degrained) and xylan $17 \pm 0.5 \%$ (with grain) and $14 \pm 0.5 \%$ (degrained) of the total carbohydrates. From a fermentation perspective, it is useful to consider the ratio of hexoses (including soluble, starch, and cellulose) to pentoses because Saccharomyces yeast does not ferment pentoses. Pentosans were $29 \%$ and $25 \%$ of total carbohydrates with and without grain included, respectively.

The sorghum samples were also analyzed using the detergent fiber system (Table 3). The general trends were similar to those observed for the dietary fiber analysis. Acid detergent lignin was reduced in the $b m r$ mutants, and the individual effects were additive in the double mutant. The two lignin analyses differed in the magnitude of the observed effects, ADL was reduced twice as much as Klason lignin; ADL was reduced by $33 \%$ for $b m r-6$ or $b m r-12$ and by $72 \%$ for the double mutant. Neither neutral detergent fiber nor acid detergent fiber contents were affected by the $b m r$ mutations.

The detergent fiber system is not an accurate method for determining cell wall composition when the results are compared to those measured using the dietary fiber system. Cellulose and hemicellulose measurements for the same samples differed by $17.1 \%$ and $16.8 \%$, respectively for the two protocols. It was also observed that ADL measurements were much lower than Klason lignin values. Subsequent analyses were based upon Klason lignin because it is considered more accurate than ADL [17].

Sugar and Ethanol Yields Following Dilute-Acid Pretreatments

The biomass samples were treated with dilute acid, and the cellulose either converted to glucose by the addition of cellulase enzymes or to ethanol by the co-additions of cellulases and $S$. cerevisiae. Adding cellulase and $S$. cerevisiae together allows for simultaneous saccharification and fermentation of cellulose to ethanol. For both experiments, recovered solids were washed with water following pretreatment to ensure that soluble sugars and starch did not influence the final glucose or ethanol yields. Xylose recovery was measured directly following pretreatment of the samples because dilute acid directly hydrolyzes xylan to xylose.

Reducing lignin had a highly beneficial effect for converting cellulose to glucose (Fig. 1; Table 4). From the washed pellets, only $65 \%$ of the available glucose was 
Table 2 Carbohydrate composition (g per kg, dry basis)

\begin{tabular}{|c|c|c|c|c|c|c|c|}
\hline \multirow[t]{2}{*}{ Genotype } & Soluble sugars ${ }^{\mathrm{a}}$ & Starch & Xylan & Arabinan & Cellulose & Total glucans & Total carbohydrates \\
\hline & \multicolumn{7}{|c|}{ Composition $(\mathrm{g} / \mathrm{kg}, \mathrm{db})$} \\
\hline \multicolumn{8}{|c|}{ Degrained samples } \\
\hline $\mathrm{DM}$ & $181 \pm 4$ & $25 \pm 0$ & $165 \pm 7$ & $23 \pm 3$ & $248 \pm 3$ & 454 & 642 \\
\hline $\mathrm{DM}$ & $173 \pm 7$ & $32 \pm 1$ & $168 \pm 7$ & $23 \pm 6$ & $246 \pm 6$ & 451 & 642 \\
\hline$b m r-6$ & $157 \pm 26$ & $22 \pm 1$ & $177 \pm 0$ & $26 \pm 3$ & $256 \pm 3$ & 435 & 638 \\
\hline$b m r-6$ & $171 \pm 19$ & $19 \pm 1$ & $173 \pm 1$ & $23 \pm 0$ & $251 \pm 0$ & 441 & 637 \\
\hline$b m r-12$ & $209 \pm 1$ & $34 \pm 1$ & $174 \pm 1$ & $24 \pm 4$ & $248 \pm 4$ & 491 & 689 \\
\hline$b m r-12$ & $205 \pm 4$ & $29 \pm 0$ & $166 \pm 1$ & $22 \pm 0$ & $244 \pm 0$ & 478 & 666 \\
\hline Wild-type & $224 \pm 3$ & $39 \pm 1$ & $167 \pm 1$ & $19 \pm 1$ & $240 \pm 1$ & 503 & 688 \\
\hline Wild-type & $210 \pm 21$ & $31 \pm 1$ & $163 \pm 2$ & $20 \pm 0$ & $242 \pm 0$ & 483 & 666 \\
\hline \multicolumn{8}{|c|}{ Plant samples with grain } \\
\hline DM & $136 \pm 16$ & $143 \pm 0$ & $143 \pm 3$ & $21 \pm 2$ & $220 \pm 2$ & 499 & 663 \\
\hline DM & $132 \pm 4$ & $144 \pm 0$ & $143 \pm 2$ & $21 \pm 1$ & $197 \pm 1$ & 473 & 637 \\
\hline$b m r-6$ & $142 \pm 18$ & $94 \pm 1$ & $143 \pm 2$ & $20 \pm 0$ & $236 \pm 0$ & 472 & 635 \\
\hline$b m r-6$ & $153 \pm 2$ & $116 \pm 0$ & $149 \pm 5$ & $21 \pm 3$ & $196 \pm 3$ & 465 & 635 \\
\hline$b m r-12$ & $151 \pm 2$ & $98 \pm 0$ & $142 \pm 4$ & $21 \pm 5$ & $266 \pm 5$ & 515 & 678 \\
\hline$b m r-12$ & $196 \pm 2$ & $117 \pm 1$ & $153 \pm 4$ & $22 \pm 3$ & $242 \pm 3$ & 555 & 730 \\
\hline Wild-type & $141 \pm 5$ & $114 \pm 0$ & $137 \pm 0$ & $20 \pm 1$ & $253 \pm 1$ & 508 & 665 \\
\hline Wild-type & $191 \pm 5$ & $107 \pm 2$ & $147 \pm 6$ & $20 \pm 7$ & $229 \pm 7$ & 527 & 694 \\
\hline
\end{tabular}

Total glucans $=$ soluble sugars + starch + cellulose

$D M$ double mutant

${ }^{a}$ Includes glucose, fructose, and sucrose

recovered by enzymatic hydrolysis for wild-type biomass. In contrast, the recovery of glucose for the double mutant was $88 \%$. Glucose yields were found to be strongly and negatively correlated with Klason lignin contents ( $R=-0.971$ no grain; $R=-0.880$ with grain). The strong correlation is encouraging because the crops were field grown, suggesting that the beneficial effects of lowering lignin were not suppressed by environmental differences, at least in this study. In contrast, reducing lignin content did not affect xylose yields (Fig. 2; Table 4) because the xylan was almost completely hydrolyzed for all the samples. This result may also explain the strong correlation between lignin reduction and glucose released by cellulase hydrolysis; if xylan was released during pretreatment, only lignin and cellulose would be left behind in the washed pellet.

Ethanol yields also dramatically benefitted from reducing lignin content (Fig. 3; Table 4). Ethanol yields for the degrained samples increased by $17 \%$ for the single $b m r$ mutants and $46 \%$ for the double mutant. The highest ethanol yield (54.5\%) was obtained using the double mutant. As was the case for glucose yield, most of the variation in ethanol yields can be attributed to differences in Klason lignin contents. The correlations between ethanol efficiency and lignin contents were -0.943 and -0.849 for samples processed without and with grain, respectively.
Electron Microscopy of Wild-Type and Double-Mutant Samples

We performed electron microscopy of dilute-acid treated tissues to gain insight into the ultrastructural changes that occur with samples of divergent lignin amounts. Untreated biomass samples from both wild-type and double-mutant plants appeared to be similar (Fig. $4 a, b$ and e, f, respectively). In contrast, samples subjected to dilute-acid pretreatment exhibited less overall electron density and showed the appearance of many electron-dense globules. The relative amounts and size of these globules were different for these two samples. In samples from wild-type plants, there were a number of smaller globules dispersed throughout the cell walls (Fig. 4c, d arrows). In the samples from double-mutant plants, these globules were considerably larger and appeared to be caught flowing toward the periphery of cell walls (Fig. 4e, f arrows).

Ethanol Yields Following Alkaline Pretreatments

Reaction conditions for the dilute-acid pretreated applied above was chosen to emphasize differences between cultivars as opposed to optimize conversion yields. To determine the yield potential that could be achieved with a 
Table 3 Detergent fiber analysis composition (g per kg, dry basis)

\begin{tabular}{|c|c|c|c|c|c|}
\hline \multirow[t]{2}{*}{ Genotype } & Neutral detergent fiber & Acid detergent fiber & Acid detergent lignin & Cellulose $^{\mathrm{a}}$ & Xylan $^{\mathrm{b}}$ \\
\hline & \multicolumn{5}{|c|}{ Composition (g per kg, db) } \\
\hline \multicolumn{6}{|c|}{ Degrained Samples } \\
\hline $\mathrm{DM}$ & 462 & 327 & 7.1 & 320 & 135 \\
\hline $\mathrm{DM}$ & 478 & 302 & 8.8 & 293 & 176 \\
\hline$b m r-6$ & 453 & 317 & 18.1 & 299 & 136 \\
\hline$b m r-6$ & 457 & 301 & 19.7 & 281 & 156 \\
\hline$b m r-12$ & 472 & 287 & 20.3 & 267 & 185 \\
\hline$b m r-12$ & 463 & 307 & 17.5 & 290 & 156 \\
\hline Wild-type & 465 & 288 & 25.4 & 263 & 177 \\
\hline Wild-type & 473 & 350 & 30.7 & 319 & 123 \\
\hline \multicolumn{6}{|c|}{ Plant samples with grain } \\
\hline $\mathrm{DM}$ & 428 & 272 & 13.2 & 259 & 156 \\
\hline DM & 404 & 293 & 8.5 & 285 & 111 \\
\hline$b m r-6$ & 412 & 299 & 20.1 & 279 & 113 \\
\hline$b m r-6$ & 412 & 269 & 23.1 & 246 & 143 \\
\hline$b m r-12$ & 421 & 278 & 18.9 & 259 & 143 \\
\hline$b m r-12$ & 415 & 248 & 21.7 & 226 & 167 \\
\hline Wild-type & 444 & 314 & 30.0 & 284 & 130 \\
\hline Wild-type & 426 & 263 & 28.5 & 235 & 135 \\
\hline
\end{tabular}

$D M$ double-mutant

${ }^{\mathrm{a}}$ Cellulose $=\mathrm{ADF}-\mathrm{ADL}$

${ }^{\mathrm{b}}$ Xylan $=\mathrm{NDF}-\mathrm{ADF}$

more effective pretreatment, the biomass samples were treated with dilute ammonium hydroxide at $170^{\circ} \mathrm{C}$ for $20 \mathrm{~min}$. Ammonium hydroxide was selected for the higher temperature pretreatment, in part because it produces fewer side products that are inhibitory to subsequent fermentation. This was an important consideration because the whole hydrolysate was fermented (as opposed to the washed solids) to ensure the highest possible yield. Despite the differences in the pretreatment conditions, reduced lignin still had a beneficial effect. There was a direct one-to-one correspondence between greater ethanol efficiency and reduction in lignin content (Fig. 5). The overall ethanol yield was increased to 116.0 and $129.9 \mathrm{mg}$ ethanol/g beginning biomass, dry basis, for the double-mutant plants compared to 98.4 and $113.2 \mathrm{mg} / \mathrm{g}$ for wild-type sorghums. Ethanol yields do not reflect release of pentoses because $S$. cerevisiae is unable to ferment them. Samples were also evaluated using plant biomass processed with the grain intact. While ethanol efficiencies were increased compared to the dilute-acid pretreatment (data not shown), the benefit of reduced lignin was not observable presumably because much of the ethanol originated from starch present within the grains.

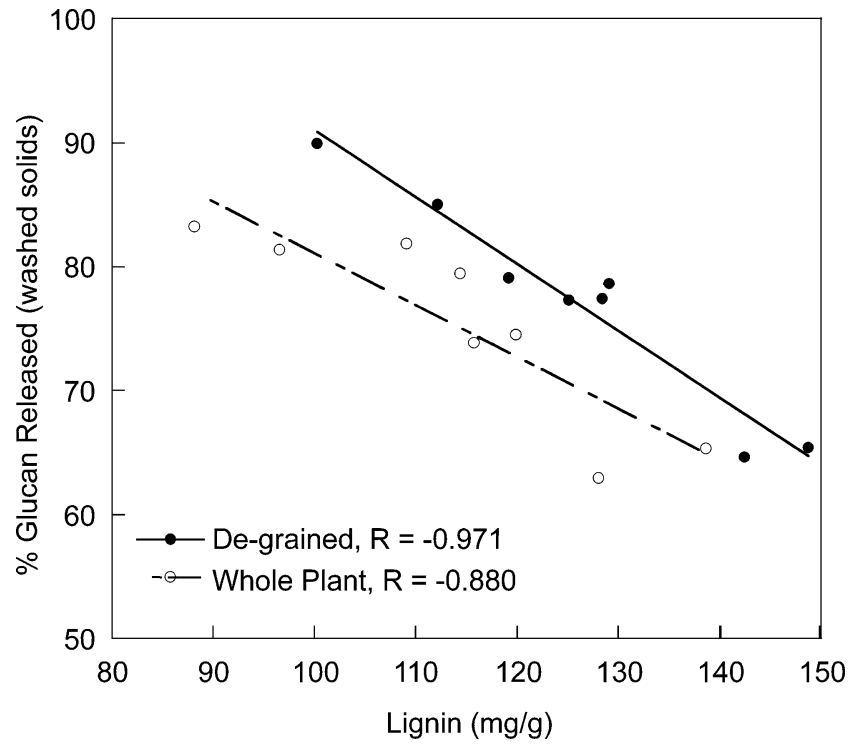

Fig. 1 Glucose recovery efficiencies for wild-type and $b m r$ mutants with various lignin contents. Samples were pretreated with dilute acid, washed to remove extractable materials, and treated with cellulase. Data plotted for with grain and degrained plant samples. Experiments were performed in triplicate 
Table 4 Enzymatic release of sugars and ethanol fermentation results (\% of maximum)

\begin{tabular}{|c|c|c|c|c|}
\hline \multirow[t]{2}{*}{ Genotype } & \multirow[t]{2}{*}{ Klason lignin $(\mathrm{g} / \mathrm{kg})$} & Glucose released & Xylose released & Ethanol efficiency \\
\hline & & \multicolumn{3}{|c|}{ Units ( $\%$ of maximum) } \\
\hline \multicolumn{5}{|c|}{ Degrained samples } \\
\hline $\mathrm{DM}$ & 112 & $85.0 \pm 1.0$ & $101.7 \pm 1.3$ & $52.2 \pm 7.8$ \\
\hline DM & 100 & $89.9 \pm 4.5$ & $101.5 \pm 0.2$ & $56.8 \pm 8.7$ \\
\hline$b m r-6$ & 129 & $78.6 \pm 3.3$ & $94.2 \pm 2.3$ & $44.3 \pm 2.1$ \\
\hline$b m r-6$ & 119 & $79.1 \pm 4.0$ & $97.2 \pm 5.1$ & $43.7 \pm 5.9$ \\
\hline bmr-12 & 125 & $77.3 \pm 1.4$ & $89.4 \pm 4.9$ & $45.8 \pm 4.3$ \\
\hline$b m r-12$ & 128 & $77.4 \pm 3.8$ & $104.2 \pm 4.2$ & $40.8 \pm 5.8$ \\
\hline Wild-type & 143 & $64.6 \pm 1.9$ & $95.8 \pm 1.8$ & $36.2 \pm 3.1$ \\
\hline Wild-type & 149 & $65.4 \pm 2.0$ & $96.9 \pm 5.9$ & $38.2 \pm 2.6$ \\
\hline \multicolumn{5}{|c|}{ Plant samples with grain } \\
\hline DM & 97 & $81.3 \pm 5.1$ & $98.8 \pm 4.4$ & $48.9 \pm 2.5$ \\
\hline $\mathrm{DM}$ & 88 & $83.2 \pm 4.1$ & $101.2 \pm 1.8$ & $46.8 \pm 6.5$ \\
\hline$b m r-6$ & 114 & $79.4 \pm 2.1$ & $100.3 \pm 1.5$ & $41.6 \pm 4.5$ \\
\hline$b m r-6$ & 109 & $81.8 \pm 3.6$ & $99.2 \pm 0.1$ & $45.6 \pm 4.4$ \\
\hline$b m r-12$ & 120 & $74.5 \pm 2.0$ & $104.8 \pm 1.3$ & $39.9 \pm 0.8$ \\
\hline$b m r-12$ & 116 & $73.8 \pm 2.8$ & $96.4 \pm 0.8$ & $46.3 \pm 6.5$ \\
\hline Wild-type & 139 & $65.3 \pm 3.5$ & $101.0 \pm 1.8$ & $35.8 \pm 3.3$ \\
\hline Wild-type & 128 & $62.9 \pm 3.1$ & $94.6 \pm 4.0$ & $33.1 \pm 3.6$ \\
\hline
\end{tabular}

\section{Discussion}

Most of the carbohydrates available for conversion to ethanol are associated with the plant cell walls. For our forage sorghum samples, $67.6 \pm 3.3 \%$ of the carbohydrates originated from cell walls, excluding the contribution of the

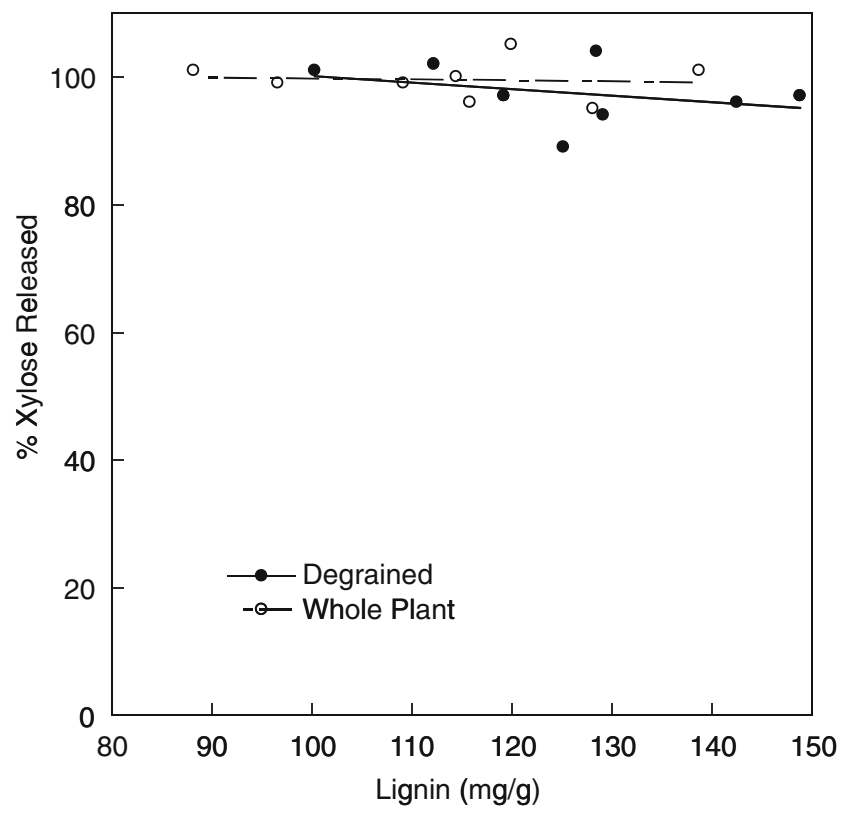

Fig. 2 Xylose recovery efficiencies for wild-type and $b m r$ mutants with various lignin contents. Xylan was hydrolyzed by treating with dilute acid. Data plotted for with grain and degrained plant samples. Experiments were performed in triplicate grain. However, there are significant amounts of soluble sugars present, which is not entirely beneficial. While these sugars are directly available for fermentation, they may also rapidly degrade during (especially dilute-acid) pretreatment [7]. As such, the sugars may need to be extracted prior to pretreatment. Releasing the structural carbohydrates for

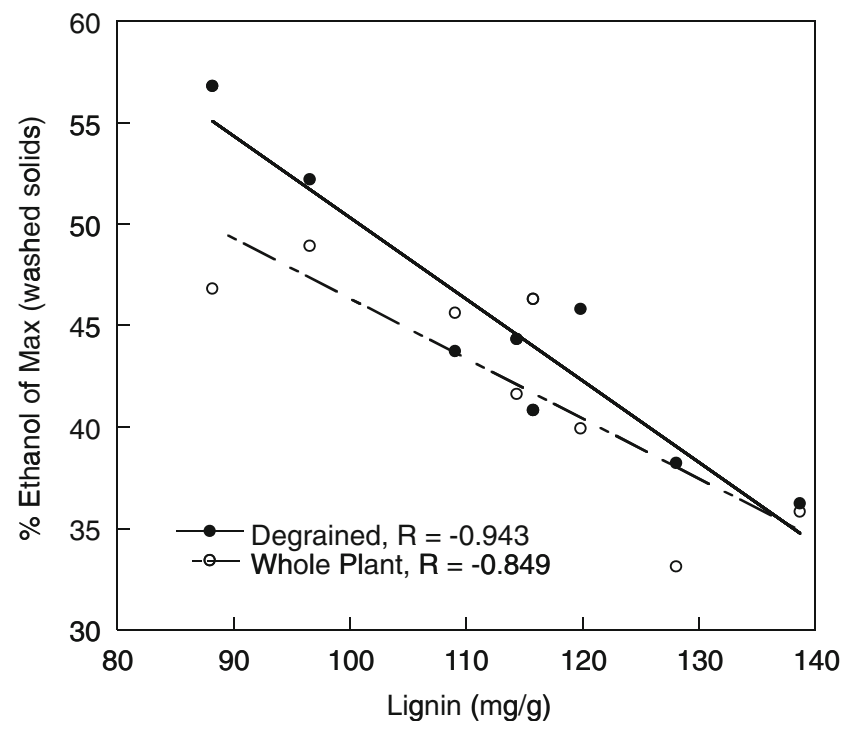

Fig. 3 Ethanol conversion efficiencies for wild-type and $b m r$ mutants with various lignin contents. Samples were pretreated with dilute acid, washed to remove extractable materials, and fermented using $S$. cerevisiae in the presence of cellulase. Data plotted for with grain and degrained plant samples. Experiments were performed in triplicate 

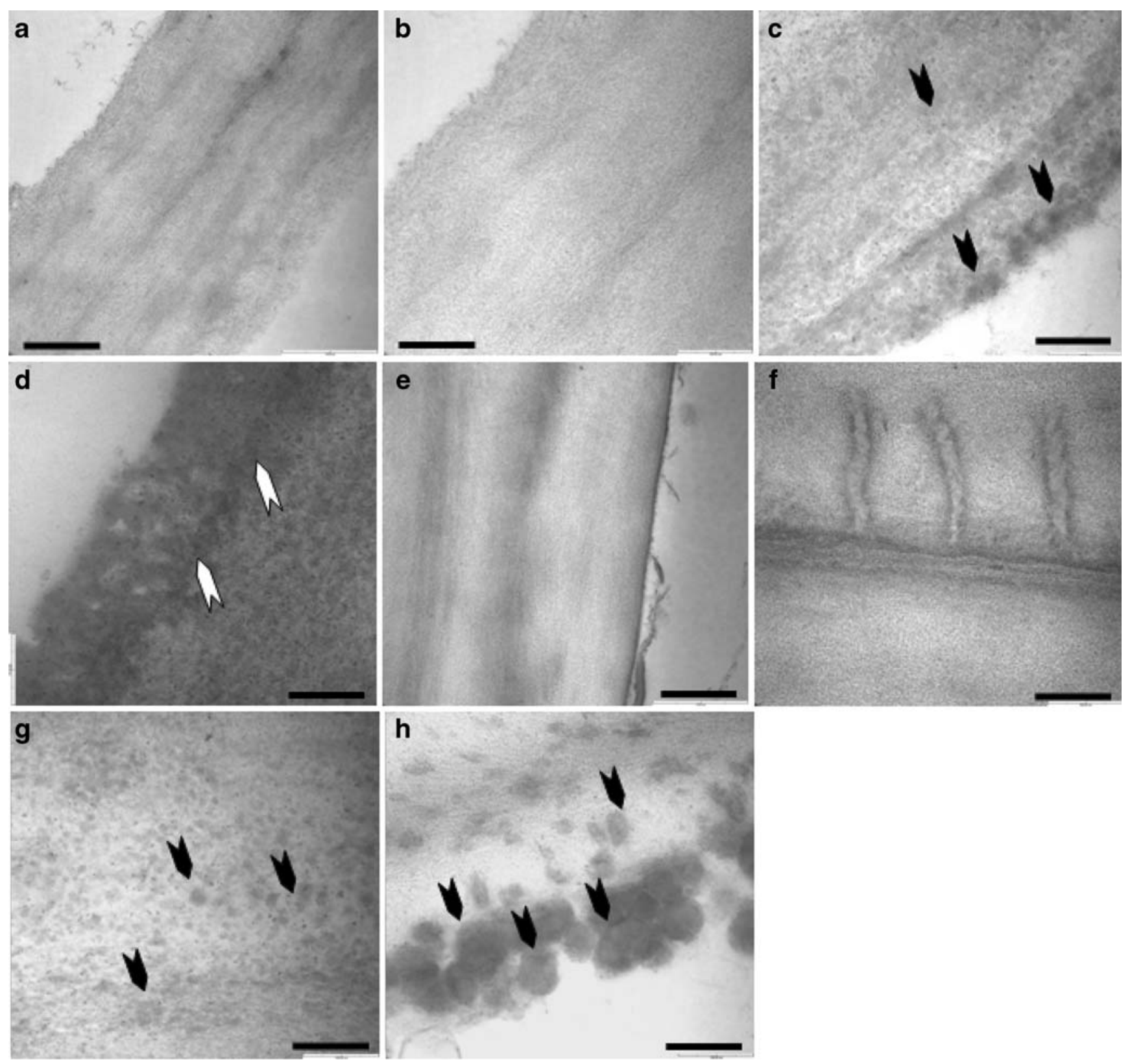

Fig. 4 TEM images of sorghum biomass samples: a, b wild-type untreated; c, d wild-type pretreated with dilute acid and washed with distilled water; $\mathbf{e}, \mathbf{f}$ double-mutant untreated; and $\mathbf{g}, \mathbf{h}$ double mutant pretreated and washed. Arrows indicate areas of lignin coalescence

fermentation is problematic because they are embedded in a complex matrix consisting of hemicellulose, lignin (present in secondary cell walls), and cellulose [34]. In particular, conversion of cellulose is dependent upon enzymatic hydrolysis of the polymer to glucose using cellulases. It is well established that the limiting factor for enzymatic hydrolysis of cellulose is access of the individual glucan fibers to the cellulase enzyme [16]. The major barriers impeding this access are the crystalline nature of cellulose, hemicellulose (e.g., GAX), and lignin. While GAX can be and formation of globules within and on the periphery of cell walls. Bars at the bottom of micrographs $\mathbf{a}, \mathbf{c}, \mathbf{e}$, and $\mathbf{g}$ are approximately $400 \mathrm{~nm}$. Bars at the bottom of micrographs $\mathbf{b}$, $\mathbf{d}$, f, and $\mathbf{h}$ are approximately $200 \mathrm{~nm}$

extracted from the cellulose fibers by pretreating the biomass prior to enzyme addition, lignin is difficult to remove because it comprises hydrophobic aromatic monomers interconnected through recalcitrant chemical linkages.

In this study, a unique set of forage sorghum (cv Atlas) samples were used to explore the role of lignin as a barrier for cellulose hydrolysis in more detail. The set included four near-isogenic lines: wild type, $b m r-6, b m r-12$, and $b m r-6 b m r-12$. Because they are near isogenic, the effect of reduced lignin could be studied independent of other 


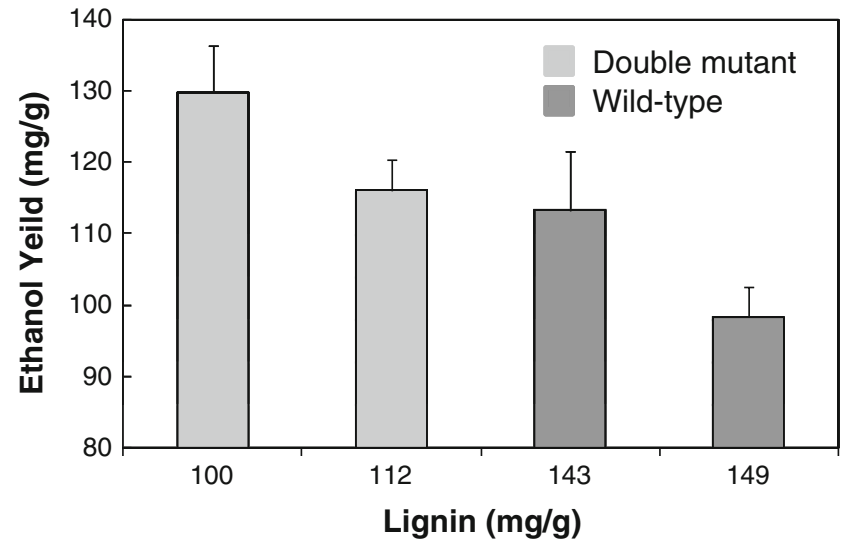

Fig. 5 Ethanol conversion yields for wild-type and double mutants. Samples were pretreated with dilute ammonia hydroxide and fermented using $S$. cerevisiae in the presence of cellulase. Data only shown for degrained samples. Experiments were performed in triplicate

genetic loci that may affect biomass conversion yield not associated with lignin concentration. As expected, the $b m r$ mutations resulted in lower lignin contents compared to the parental line: $b m r-6$ or $b m r-12$ reduced the lignin content by $15 \%$ and $13 \%$, respectively, and $b m r-6 b m r-12$ double mutant reduced lignin by of $27 \%$. Therefore, $b m r-6$ and $b m r-12$ were equally effective in reducing lignin content, and introducing both had double the effect of either alone. Our results are comparable to an earlier study using $b m r-6$ and $b m r-12$, which reported $17 \%$ and $13 \%$ decreases, respectively [27]. The samples in the present study were also analyzed for ADL, which followed a similar trend observed for Klason lignin. These results in general were similar to those observed by earlier studies for grain and forage sorghum mutants $b m r-6$ and $b m r-12$ especially for the former study [20, 21].

It is somewhat surprising that $b m r-6$ and $b m r-12$ had nearly identical effects on lignin because each affect independent steps in monolignol biosynthesis and alter lignin composition in different ways. Likewise, it was unexpected that both effects would be additive for the double mutant because each mutant has unique lignin compositions. The bmr-6 nearly abolishes cinnamylalcohol dehydrogenase activity in young internodes [23] and causes decreased incorporation of $p$-coumaric acid esters and G-, S-, and H-lignin units into cell walls but does not appear to reduce ferulate incorporation. These data are consistent with the hypothesis that lowered levels of sinapyl alcohol in $b m r-6$ plants also interfere specifically with sinapoyl- $p$-coumarate levels. Generally, $b m r-6$ plants possessed greater G-indene as compared to wild-type plants. The second mutation, $b m r-12$, is a null mutation of a specific caffeic acid $O$-methyltransferase (COMT) [2]. This mutation results in the complete loss of COMT protein in stem extracts [23] and depresses $p$-coumarate ester levels in cell walls but not to the extent of the $b m r-6$ mutation. Nearisogenic lines of sorghum containing the $b m r-12$ mutation exhibit significant reduction in S-lignin moieties and much lower reductions in G- and H-lignin monomers. There was also increased incorporation of 5-OHG-lignin in these plants [23], indicating that the $b m r-12$ encodes for a 5hydroxyconiferylaldehyde- $O$-methyltransferase, consistent with similar mutations in other plants [1, 18]. Finally, all lignin moieties were reduced in the double-mutant plants [23].

From a conversion perspective, optimal recovery of both pentoses and hexoses is required. For biomass obtained from these forage sorghum lines, a low-severity dilute-acid pretreatment (e.g., $121^{\circ} \mathrm{C}$ for $1 \mathrm{~h}$ ) was highly effective in hydrolyzing xylan. On average for all samples, $98.6 \pm 4.0 \%$ of the xylan was recovered as xylose, and individual xylose recoveries were not correlated with lignin content. Corredor et al. [5] also found that the $b m r$ mutation did not affect pentose recoveries for dilute-acid pretreated sorghum $(2 \%$ $\mathrm{H}_{2} \mathrm{SO}_{4}, 140^{\circ} \mathrm{C}, 30 \mathrm{~min}$ ), though their xylose recoveries were only $84 \%$ and $86 \%$. In an earlier study [7], varying maturities of switchgrass and canary reed grass were pretreated using similar conditions reported here. In this study, maturity was determined not to influence xylose recoveries even though overall lignin contents increased with greater maturity. These data suggest that, from a biorefinery context, lignin concentration may not exert an influence on xylose recoveries in herbaceous energy crops such as sorghum.

Lignin content did impact cellulose digestion by cellulase. Differences in recoveries among samples were strongly and inversely correlated with lignin content $(r=-0.971$ (grain removed) and $r=-0.880$ (with grain)) Another study [27] also observed a similar range of cellulose conversion efficiencies of $59 \%$ and $71 \%$ for $b m r-6$ and $b m r-12$ plants, respectively, when treated with dilute sulfuric acid $\left(1.3 \% \mathrm{w} / \mathrm{w}, 121^{\circ} \mathrm{C}, 40 \mathrm{~min}\right)$. However, a difference was observed in the effectiveness of $b m r-6(7 \%)$ and $b m r-12(21 \%)$ for improving glucose efficiencies. In contrast, we observed similar results for $b m r-6$ and $b m r-12$ mutants, $12 \%$ and $16 \%$, respectively. Notably, in the cited study, cellulose conversions were similar for the $b m r-6$ and $b m r-12$ mutants. So, the observed differences for $b m r-6$ and $b m r-12$ did not originate from the mutants but rather from differences in the bmr-6 and bmr-12 controls. In our study, the samples were from near-isogenic lines, and the same control sample (e.g., wild type) was used for all comparisons. A different study [5] also compared differences in glucose yields for a $b m r$ mutant vs. a wild type and observed a $64 \%$ improvement for the former, which is a much greater effect than was observed here. However, their conversion efficiency for the wild type was only $48 \%$, and so differences between the two studies might have arisen 
from their more stringent comparison in terms of pretreatment condition and cellulase loading. All three studies are consistent in one finding: lowering lignin content improves glucose recoveries for forage sorghum plants.

The ability of lowering lignin contents to improve the response of cellulose to cellulase digestion appears to be general. In one study [4], lignin-modified alfalfa plants were evaluated for sugar yields following treatments with dilute acid and cellulase enzymes. A total of six transgenic lines with down-regulated lignin synthesis were constructed by expressing antisense constructs. They also observed a strong negative correlation between sugar release following enzymatic treatment and lignin content $(r=-0.897)$. In another study [7], a set of six samples were used that varied by species and harvest maturity. The samples were each treated with dilute acid and cellulase and evaluated for glucose yields. Despite the wide differences among samples, when cellulose conversion was plotted against lignin content, the correlation was -0.85 . Other studies describing the effect of lignin content on cellulose conversions are discussed in the following reviews $[3,6,19]$.

While the effect of lowering lignin content on rumen digestibility and cellulose enzymatic conversion is well established, this is not true for the effect of varying lignin composition. There have been conflicting reports with regards to the influence of the $G$ to $S$ ratio on rumen digestibility [13] and enzymatic release of sugars from pretreated biomass $[4,27]$. In this study, the alteration to lignin composition was not a factor that influenced product yields because the $b m r-6$ and $b m r-12$ plants had similar glucose yields, although they displayed marked differences in lignin composition [23, 29].

In this study, ethanol yield efficiencies varied from $33.6 \%$ to $52.2 \%$ for the forage sorghum samples, and ethanol yields improved directly with reduced lignin contents ( $r=0.943$ (degrained) and $r=0.849$ (with grain)) The ethanol efficiencies were lower than observed for glucose digestion. Some of the lower efficiency is associated with the yeast diverting carbon to products other than ethanol. It is also possible that microbial inhibitors formed during dilute-acid pretreatment-impeded ethanol fermentation, though there was no residual glucose detected after fermentation (data not shown). The major cause for the reduced yield is probably lower cellulase activities in the SSF compared to direct digestion. As is standard, the SSFs were conducted with $75 \%$ less cellulase per gram cellulose than added for the direct digestions. Furthermore, the presence of yeast in the SSFs limits the fermentation temperature to $35^{\circ} \mathrm{C}$ vs. $50^{\circ} \mathrm{C}$ for the enzyme-only digestions.

Electron microscopy images taken of wild-type and double-mutant biomass samples following dilute-acid treatment suggest a possible mechanism for the phenomena observed for product yields. Prior research has shown that droplets formed following dilute-acid pretreatment of corn stover comprise lignin droplets [10]. The images indicate what we can reasonably presume to be lignin coalescence during pretreatment for wild type and the double mutant but that the size of lignin-containing droplets were apparently greater in the tissues obtained from double-mutant plants compared to wild-type. These images are consistent with acid treatment resulting in a greater release of lignin from the biomass of double mutant relative to wild type, which should make the cellulose fibers more accessible for cellulase in the former.

Alkaline pretreatments are known to be particularly effective for processing lignocellulose from warm season grasses for ethanol fermentation [6]. However, the potential for $b m r$ mutations to improve process efficiencies is unknown. For this experiment, the dilute ammonium hydroxide pretreatment process was chosen because ammonia can be removed following pretreatment by evaporation, and the end material is highly fermentable. Ammonium hydroxide pretreatment has been shown to be effective for processing corn stover [15]. The doublemutant and wild-type biomass samples were pretreated with dilute ammonium hydroxide $\left(170^{\circ} \mathrm{C}, 20 \mathrm{~min}\right)$ and the glucans converted to ethanol by SSF using $S$. cerevisiae. The ethanol yields ranged from 98.4 to $129.9 \mathrm{mg} / \mathrm{g}$ dry biomass and were highest for the $b m r$ mutant samples. These yields could be improved if a microorganism had been used that could ferment pentoses. Still, the ethanol yields were higher than observed for the dilute-acid pretreatments probably because of the greater reaction temperature used for the ammonium hydroxide pretreatment. On a relative basis, the effect of reducing lignin content was less than that observed with the dilute-acid pretreatment. This reduced effect is likely due to the overall greater effectiveness of the alkali pretreatment.

From this study, it can be concluded that reducing lignin content can greatly benefit conversion efficiencies of lignocellulose to sugars and ethanol. The influence was especially pronounced for samples treated with dilute acid at lower severities, but significant gains were also found for those treated with ammonium hydroxide. Furthermore, conversion efficiencies were strongly correlated with lignin content. Prior studies have also reported beneficial effects from reducing lignin contents by genetic alterations or pretreatment strategies. Much of the current research into breeding superior energy crop plants $[33,35,36]$ is directed towards modifying lignin composition and/or contents. Results from this study support this emphasis.

Acknowledgments The authors would like to thank Ms. Patricia J. O'Bryan, Mr. Loren Iten, and John J. Toy for their fine technical assistance. 


\section{References}

1. Barrière $\mathrm{Y}$, Ralph $\mathrm{J}$, Méchin V, Guillaumie S, Grabber JH, Argillier O et al (2004) Genetic and molecular basis of grass cell wall biosynthesis and degradability. II. Lessons from brownmidrib mutants. Comptes Rendus Biologies 327:847-860

2. Bout S, Vermerris W (2003) A candidate-gene approach to clone the sorghum brown midrib gene encoding caffeic acid $O$-methyltransferase. Mol Genet Genomics 269:205-214

3. Chang VS, Holtzapple MT (2000) Fundamental factors affecting biomass enzymatic reactivity. Appl Biochem Biotechnol - Part A Enzyme Eng Biotechnol 84-86:5-37

4. Chen F, Dixon RA (2007) Lignin modification improves fermentable sugar yields for biofuel production. Nat Biotechnol 25:759-761

5. Corredor DY, Salazar JM, Hohn KL, Bean S, Bean B, Wang D (2008) Evaluation and characterization of forage sorghum as feedstock for fermentable sugar production. Appl Biochem Biotechnol, 1-16

6. Dien BS, Iten LB, Skory CD (2005) Converting herbaceous energy crops to bioethanol: a review with emphasis on pretreatment processes. In: Hou CT (ed) Handbook of industrial biocatalysis. CRC Press LLC, Boca Raton, FL pp 1-11

7. Dien BS, Jung HJG, Vogel KP, Casler MD, Lamb JFS, Iten L et al (2006) Chemical composition and response to dilute-acid pretreatment and enzymatic saccharification of alfalfa, reed canarygrass, and switchgrass. Biomass Bioenergy 30:880-891

8. Dien BS, Nagle N, Hicks KB, Singh V, Moreau RA, Tucker MP et al (2004) Fermentation of "Quick Fiber" produced from a modified corn-milling process into ethanol and recovery of corn fiber oil. Appl Biochem Biotechnol-Part A Enzyme Eng Biotechnol 115:937-949

9. Dien BS, Ximenes EA, O’Bryan PJ, Moniruzzaman M, Li XL, Balan V et al (2008) Enzyme characterization for hydrolysis of AFEX and liquid hot-water pretreated distillers' grains and their conversion to ethanol. Bioresour Technol 99:5216-5225

10. Donohoe BS, Decker SR, Tucker MP, Himmel ME, Vinzant TB (2008) Visualizing lignin coalescence and migration through maize cell walls following thermochemical pretreatment. Biotechnol Bioeng 101:913-925

11. Dowe N, McMillan J (2001) SSF experimental protocolslignocellulosic biomass hydrolysis and fermentation laboratory analytical procedure (LAP). In: DOE (ed) National renewable energy laboratory, p 19

12. Farrell AE, Plevin RJ, Turner BT, Jones AD, O’Hare M, Kammen DM (2006) Ethanol can contribute to energy and environmental goals. Science 311:506-508

13. Grabber JH (2005) How do lignin composition, structure, and cross-linking affect degradability? A review of cell wall model studies. Crop Sci 45:820-831

14. Hall MB (2001) Factors affecting starch analysis of feeds. Cooperative extension service. Institute of Food and Agricultural Sciences. University of Florida, Gainesville, FL

15. Hennessey S, Friend J, Dunson J, Tucker MP, Elander R, Hames B (2006) Integration of alternative feedstreams in biomass treatment utilization. In: E.I.D.d.N.a. Company (ed) U.S.

16. Jeoh T, Ishizawa CI, Davis MF, Himmel ME, Adney WS, Johnson DK (2007) Cellulase digestibility of pretreated biomass is limited by cellulose accessibility. Biotechnol Bioeng 98:112-122

17. Jung H-JG, Varel VH, Weimer PJ, Ralph J (1999) Accuracy of klason lignin and acid detergent lignin methods as assessed by bomb calorimetry, pp 2005-2008

18. Li L, Popko JL, Umezawa T, Chiang VL (2000) 5-Hydroxyconiferyl aldehyde modulates enzymatic methylation for syringyl monolignol formation, a new view of monolignol biosynthesis in angiosperms, pp 6537-6545
19. Mosier N, Wyman C, Dale B, Elander R, Lee YY, Holtzapple M (2005) Features of promising technologies for pretreatment of lignocellulosic biomass. Bioresour Technol 96:673-686

20. Oliver AL, Pedersen JF, Grant RJ, Klopfenstein TJ (2005) Comparative effects of the sorghum bmr-6 and bmr-12 genes: I. Forage sorghum yield and quality. Crop Sci 45:2234-2239

21. Oliver AL, Pedersen JF, Grant RJ, Klopfenstein TJ, Jose HD (2005) Comparative effects of the sorghum bmr-6 and bmr-12 genes: II. Grain yield, stover yield, and stover quality in grain sorghum. Crop Sci 45:2240-2245

22. Padmore JM (1990) Protein (crude) in animal feed - dumas method, method no. 968.06. In: Herlich K (ed) Official methods of analysis of the association of official analytical chemists, 15th edn. AOAC Inc., Arlington, VA, pp 71-72

23. Palmer N, Sattler S, Saathoff A, Funnell D, Pedersen J, Sarath G (2008) Genetic background impacts soluble and cell wall-bound aromatics in brown midrib mutants of sorghum. Planta 229:115127

24. Pedersen JF, Toy JJ, Funnell DL, Sattler SE, Oliver AL, Grant RA (2008) Registration of BN611, AN612, BN612, and RN613 sorghum genetic stocks with stacked bmr-6 and bmr-12 genes. J Plant Reg 2:258-262

25. Perlack R, Wright L, Turhollow A, Graham R, Stokes B, Erbach D (2005) Biomass as feedstock for a bioenergy and bioproducts industry: the technical feasibility of a billion-ton annual supply. In: DOE (ed). Oak Ridge National Laboratory, pp 78

26. Porter KS, Axtell JD, Lechtenberg VL, Colenbrander VF (1978) Phenotype, fiber composition, and in vitro dry matter disappearance of chemically induced brown midrib (bmr) mutants of sorghum. Crop Sci 18:205-208

27. Saballos A, Vermerris W, Rivera L, Ejeta G (2008) Allelic association, chemical characterization and saccharification properties of brown midrib mutants of sorghum (Sorghum bicolor (L.) Moench). BioEnergy Res 1:193-204

28. Sarath G, Mitchell RB, Sattler SE, Funnell D, Pedersen JF, Graybosch RA (2008) Opportunities and roadblocks in utilizing forages and small grains for liquid fuels. J Ind Microbiol Biotechnol 35:343-354

29. Sattler SE, Saathoff AJ, Haas EJ, Palmer NA, Funnell-Harris DL, Sarath G et al (2009) A nonsense mutation in a cinnamyl alcohol dehydrogenase gene is responsible for the sorghum brown midrib 6 phenotype. Plant Physiol 150(2):584-595

30. Selig M, Weiss N, Ji Y (2008) Enzymatic saccharification of lignocellulosic biomass; laboratory analytical procedure. In: DOE (ed) National Renewable Research Laboratory, p 8

31. Sluiter A, Hames B, Ruiz R, Scarlata C, Sluiter J, Templeton D et al (2008) Determination of structural carbohydrates and lignin in biomass; laboratory analytical procedure. In: DOE (ed) National Renewable Energy Laboratory, p 16

32. van Soest PJ, Robertson JB, Lewis BA (1991) Methods for dietary fiber, neutral detergent fiber, and nonstarch polysaccharides in relation to animal nutrition, pp 3583-3597

33. Vermerris W, Saballos A, Ejeta G, Mosier NS, Ladisch MR, Carpita NC (2007) Molecular breeding to enhance ethanol production from corn and sorghum stover. Crop Sci 47:S-142-153

34. Vogel J (2008) Unique aspects of the grass cell wall. Curr Opinion Plant Biol 11:301-307

35. Vogel KP, Jung H-JG (2001) Genetic modification of herbaceous plants for feed and fuel. Critical Rev Plant Sci 20:15-49

36. Weng J-K, Li X, Bonawitz ND, Chapple C (2008) Emerging strategies of lignin engineering and degradation for cellulosic biofuel production. Curr Opin Biotechnol 19:166-172

37. Wescott PC (2007) Ethanol expansion in the United States. How will the agricultural sector adjust? Economic Research Service of the U.S.D.A., pp 1-18 